\title{
Computer automation of biofeedback training
}

\author{
ALAN T. POPE and CHARLES D. GERSTEN \\ FDR Veterans Administration Health Care Facility, Montrase, New York 10548
}

\begin{abstract}
A computer-automated system has been developed for implementing response-contingent training strategies in EMG biofeedback-assisted relaxation training. An on-line minicomputer is programmed to (1) monitor progress within a training session as reflected in EMG signals; (2) compare the progress data with criteria set by the operator at the beginning of the session; and (3) on the basis of these comparisons, periodically adjust feedback gain (sensitivity) and make changes in the within-session training sequence. The system is designed to allow various adaptive training strategies to be software programmable. One of these strategies, a "shaping" procedure commonly employed in EMG biofeedback training, gradually increases the degree of relaxation necessary to produce the desired feedback signal by increasing feedback gain as the subject gets better at relaxing. Implementation of the shaping procedure is described as an illustration of system function. Current system development is guided by principles from adaptive testing and teaching systems to make more of the feedback training process adaptive in function.
\end{abstract}

Electromyographic (EMG) biofeedback-assisted relaxation training is employed in the treatment of psychophysiological disorders associated with muscle tension (Blanchard \& Young, 1974; Coursey, 1975). EMG biofeedback training sessions are usually relatively structured trial-by-trial procedures that are designed to promote deep muscle relaxation. The clinician commonly adapts the procedure to the individual patient by assessing the patient's progress and then giving appropriate instructions, changing the within-session training sequence, and/or modifying parameters (usually gain) of the electronic feedback system. In biofeedback research it is important to be able to specify precisely the treatment conditions and the rules by which the conditions are modified within a session.

A computer-automated system has been developed for the investigation of the effects of response-contingent training strategies in EMG biofeedback-assisted relaxation therapy. An on-line minicomputer monitors a subject's progress within a training session, as indicated by physiological signals and/or subject manipulanda. Utilizing the progress data together with criteria set by the operator at the beginning of the session, the computer modifies the feedback path by adjusting gain (sensitivity) and controls the training sequence by timing relaxation intervals, gating feedback signals, and selecting and presenting taped messages. Any or all of these manipulations can be made contingent upon training progress, according to some programmed training strategy.

This paper illustrates the operation of the system by describing the implementation of the "shaping" procedure generally employed in EMG biofeedback training. EMG biofeedback augments natural muscle feedback sensations by providing the subject with a tone whose pitch reflects the level of EMG activity in the monitored muscle group(s). The task of the subject is to bring the tone to a low pitch and keep it there by relaxing the muscle group(s). A shaping procedure is employed to make the task gradually more difficult as the subject gets better at relaxing (Budzynski, Stoyva, \& Adler, 1970; Cox, Freundlich, \& Meyer, 1975). This is usually done by manually increasing the gain of the feedback loop between some training trials so that increasingly more relaxation is required to produce a steady, lowpitched tone. Conversely, the gain must be decreased if the subject is not achieving a desired degree of success at keeping the pitch low. Adjustment of feedback gain serves not only to change the pitch a given EMG value produces but also to modify the sensitivity of the feedback signal to changes in the EMG signal. The aim of the shaping procedure is similar to that of adaptive testing procedures (Weiss, 1974) in that it is intended that the task be kept challenging, yet not frustrating.

\section{HARDWARE}

The hardware configuration in which the computer acts as process controller is diagrammed in Figure 1. The minicomputer is a NOVA $2 / 10$ with $24 \mathrm{~K}$ core memory, two cassette tape drives, and a Teletype console. The analog interface is an 8-channel 10-bit converter; the digital interface has 16 input lines, 16 output lines, 1 external interrupt line, and 1 strobe output line. Only those lines involved in the shaping illustration are shown in the diagram. Coulbourn Instruments modules are used for EMG signal preprocessing and feedback signal synthesis. The TTL-level lines of the digital interface are buffered to the logic level of the Coulbourn system modules.

The raw EMG signal is amplified and contour integrated to provide the relatively slow dc signal that is routed to both the $A / D$ converter and a programmable amplifier. The gain of the progammable amplifier is 


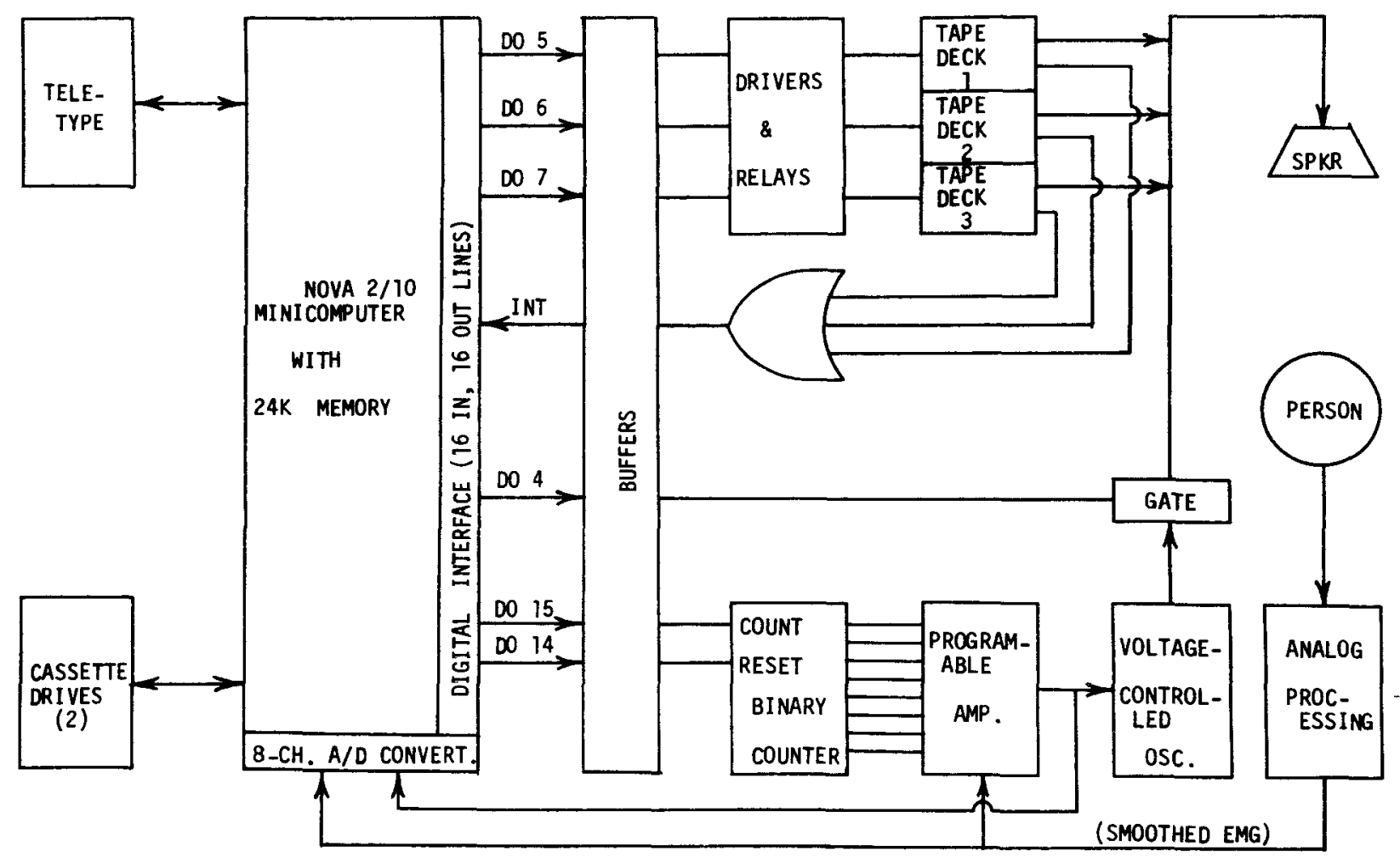

Figure 1. Hardware configuration of adaptive training system.

set by an 8-bit binary number applied to its logic inputs rather than by the usual rotary control. The gain may be adjusted in 255 discrete steps; the amplification value of each step is preselected by a slope control. The amplifier gain is programmed by an 8-bit binary counter. The counter is reset and incremented by pulses from digital output lines (DO 14 and 15). The output of the programmable amplifier controls a voltage-controlled oscillator (VCO) whose output frequency (in the range $100-3,100 \mathrm{~Hz}$ ) reflects EMG activity level. Timing and gating of this feedback signal to the subject is controlled by an additional digital output line (DO 4).

Verbal messages are presented to the subject from one channel of stereo cassette playback decks whose drives are controlled by digital output lines (DO 5, 6, and 7). The other channel of the decks is used to provide control signals that indicate to the computer the end of a particular message. These audio control signals are digitized by a Schmitt trigger and routed to the external interrupt line (INT).

\section{SOFTWARE}

The application programs are written in FORTRAN IV and run under Data General's Real-Time Operating System (RTOS). Programs are edited, compiled, assembled, and linked with necessary libraries under the Stand-alone Operating System (SOS). Programming of the analog and digital interfaces in FORTRAN IV is enabled by the Real-Time Input/Output System (RTIOS), a library of device drivers and subroutines. The digital output lines set are selected by the arguments of the real-time calls, DOLW and DOMW; the input lines are read at interrupt time by the DIW call. Sequential digital conversions of selected analog lines are executed by the AISQW call. Figure 2 is a listing of the source program of the shaping example.

\section{SHAPING ILLUSTRATION}

The flow chart of the shaping illustration program is shown in Figure 3. The console record of an abbreviated session employing the program is shown in Figure 4 . The block of text at the top of Figure 4 illustrates the session initialization interaction. The operator enters the desired value of each parameter as the program requests it. The bioamp gain is not the adjustable feedback gain; the bioamp gain is constant and is needed for calibration of the data printout. The decision rule represented by the set of parameter values illustrated may be expressed as follows: If the subject produces feedback tones of $250 \mathrm{~Hz}$ or lower for $80 \%$ or more of the previous trial duration, then the feedback gain is increased by $10 \%$ (of its maximum value). If not, the feedback gain is decreased by $20 \%$. The feedback gain is initially set at one-half of maximum. Initial gain settings 
CHANTASK 16,4

DIMENSION I VAL (2), IADDR( 3$),$ BIN(5, 36)

OIMBNSION GAIN(39), I VALO $(6)$, IDEV(1), IMASX(1), IDVAL(1)

COMMON /LABEL/IADDR, I VAL

DATA I VAL $/ 2 * 8$,

DATA IADDR $256,0,1 /$

FORMAT (F7.2)

2 FORHAT (12,F7.2)

3 FORMAT (12,3X,F6.2)

ACCEPT "A/D SCALE FACTOR: ", IDIV

ACCEPT "BIOAMP GAIN (IN K): ", IBG

ACCEPT "PERCENT TIME CRITERION: ", I PTC

ACCEPT "FREQUENCY CRI TERION: ", I FRQ

ACCEPT "PERCENT GAIN INCREASE: "IIPGI

ACCEPT "PERCENT GAIN DECREASE: "IPGD

ACCEPT "INITIAL FEEDBACK GAIN (PERCENT OF MAX): ", IFG

ACCEPT "MINIMLM FEEDBACK GAIN (PERCENT OF MAX): ", IMIN

ACCEPT "NO. OF TRIALS (MAX = 30): ", I TRLS

4 ACGEPT "NO. OF BINS/TRIAL (MAX = 5): ", I ENS

ACCEPT "TRIAL INTERUAL DURATION (I.Y SECS):", IDUR

BNS=I BNS

BDUR $=I$ DUR/BNS

IBDUR $=I$ DUR /I EHS

IF (BDUR. EQ. I BDUR) GO TO 4

GO TO

$4 \quad I 1=1 B D U R=1 B 0$

$S M I N=(I M I N / 100) *$.

I DEV $(1)=0$

$I D E U(1)=0$
IMASK $(1)=1777771$

IVALO (1) $=2000 \mathrm{~K}$

I VALO $(2)=4006 \mathrm{~K}$

I VALO $(3)=1900 \mathrm{~K}$

IVALO $(A)=400 \mathrm{~K}$

I VALO $(5)=1$

IVALO $(6)=2$

$S E T=(1 F G / 100) *$.

IF (SET.LE.255) GO TO 300

$S E T=255$

ISET SET

DO $500 \mathrm{~N}=1,1$ TRLS

CAL

DO $310 M=1$, ISET

CALL DOHV(1, I DEV(1), I VALO (5), I, I ER)

310 CONTINUE

GAIN (N) 1 ISET

CALL DOLW(1, I DEV (1), I VALO (1), I IMASK(1), I ER

CALL FDELY (100)

CALL DIW(1, IDEV(1), I DVAL (1),MSTAT)

CALL DOLW(1, I DEV(1), I VALO (2), IMASK(1), I ER)

$B E O=B$

DO $28 \mathrm{~J}=1.1 \mathrm{BNS}$

$\operatorname{sun} \theta$

DO $10 \quad I=1,1$

CALL AISOU 2, I ADDR, I VAL, MST

VOL $T=.042487+.19549$ AE 1 1 1 VAL (2)

IF (VOLT.GT. (IFRE-100)*(1/10日0.1) GO TO 5

BELO=BELO+

$5 \quad D I V=I D I V$

$S U M=S U M+I$ VAL $(1) / D I V$

CALL KDEIY (I)

CONTINUE

$\operatorname{BIN}(J, N)=(S U M / I 1) * I D I V$

CONTINIIE

CALL DOLW(1, I DEV(1), IVALO (1), IMASK (1), I ER)

CALL FDELY (IOE)

CALL OI H( I, I DEV( 1 ), I DVAL ( 1 ), MSTAT)

IF (N.EO. ITRLS) GO TO 500

JSET I I SET

IF $((B E L O /(100 * I D U R)) . L T .(I P T C / 100)$.$) GO TO 208$

$S E T=S E T+(I P G I / 100) \neq$,

IF (SET.LE. 255) GO TO 4 )

SET $=255$

ISET-SET

IF (ISET. EQ.JSET) GO TO 560

CALL DOLY (1, I DEV (1), IVALO (3), IMASK (1), I ER)

CALL FDELY (196)

CALL DIU(I, I DEV(I), I DVAL ( I), MSTAT)

GO TO 500

260

$S E T=S E T-(I P G D / 100) \neq$.

IT (SET.GE. SMIN) 60 TO 40

$S E T=S M I N$

461 ISET-SET

IF (ISET.EO.JSET) GO TO 500

CALL DOLW(1, I DEV (1), I VALO (4), IMASK (1), I ER

CALL FDEYC(100)

CALL DIY(1, I DEV(1), I DUAL (1),MSTAT)

CONTINUE

TYPE " AVERAGE PEAK-TO-PEAK MICROVOLTS"

DO $K=1$, I TRLS

TYPE "TRIAL NO.".,K

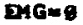

DO 601 Le 1 , I BNS

$B N=B I N(L, K)$

Figure 2. Source listing of shaping illustration.
BNCAL $=1.26748+.64972 * B N$

BINAV= 3. 14*(30/1BG) *BNCAL

WRITE(10,2) " BIN NO. ",L," ", BINAV

$E M G=E M G+B I N(L, K)$

601 CONTINUE

EMG $=$ DHG $/$ I UNS

BMCAL $=1.26748+.64972 *$ DYG

OVAV=3 - $14 *(3 B / 1 B G) *$ EMCAL

URI TE(10,1) " OUERALL ", OVAV

TYPE "<15\%"

690

CONTINUE

TYPE "GAINS"

DO 6S2 $I=1$, I TRLS

GP ER= (GAIN (1) 1255$) * 100$

URI TE(16,3) I, GPER

692

CONTINUE

BND

Figure 2 (Continued)

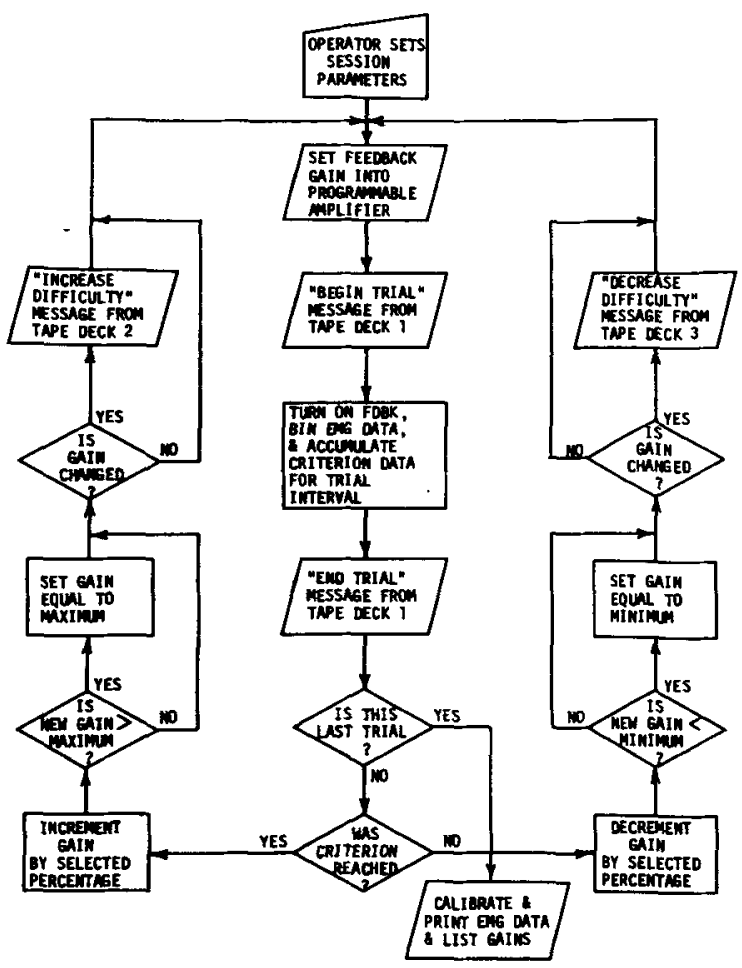

Figure 3. Flow chart of shaping illustration program.

for subsequent sessions are usually based on performance in previous sessions. The minimum gain limit is set at $20 \%$. Implementing the frequency criterion requires that the computer monitor only the programmable amplifier output (see Figure 1) and base the decision on this signal value. The "unadjusted" EMG signal is monitored only for data logging, although its values can be retrieved from the programmable amplifier signal values.

After session initialization, the trial-by-trial procedure begins (Figure 3). The subject hears a taped "readying" message before each trial and an "end of trial" message after each trial. A sufficient number of these message pairs are prerecorded, along with an introductory message preceding the first pair, for playback from Tape Deck 1. If gain is being changed, a second message 
following the trial tells the subject whether the task of maintaining steady, low-pitched tones is being made "a little harder" or "a little easier" for the next trial. These repeating messages are played back from Tape Decks 2 and 3, respectively, utilizing "endless" cassettes. The feedback-gain adjustment is made between trials, when feedback is gated off.

The lower part of the console record (Figure 4) illustrates the data logging format. The smoothed EMG signal is sampled at a $100-\mathrm{Hz}$ rate, averaged within the preselected number of equal-interval time bins, and converted to input units (peak-to-peak microvolts). An overall trial average is also obtained. Offset and slope constants written into the program for calibration of analog data (Figure 2) are derived by a separately run real-time calibration program. The calibration program determines the coefficients of the linear relationship between known calibration voltages and the integer results of the $A / D$ conversion.

At the bottom a trial-by-trial record of gain percentages is given. The first item, for example, shows that the binary equivalent of 127 was set into the programmable amplifier for the first trial. It can be seen that although the overall average EMG level was higher on Trial 2 than on Trial 1, feedback gain was decreased from Trial 1 to Trial 2, whereas it was increased from Trial 2 to Trial 3. This behavior occurs because the gainadjustment decision is based not on the "absolute" EMG level but on the feedback-signal level which is reduced on Trial 2 . Thus, the system implements the shaping decision rule described earlier. The last two items of the gain list demonstrate that, although a gain reduction of $20 \%$ was called for after Trial 5, the program would not allow the gain to fall below the preset minimum of $20 \%$.

\section{EXTENSIONS}

Various sets of session parameter values within this one strategy can be tried to examine their effects on acquisition and retention of relaxation skill. However, our work is currently directed toward investigating the effects of several training strategies in which some of the parameters themselves are subject to on-line response-contingent modification. For example, modifications in percentage step size of gain adjustment and trial interval length are based on characteristics of subject performance. Fading procedures and relaxation exercise instructions are being incorporated into some training strategies. The placement of these procedures in the within-session training sequence is also being made progress dependent.

O'Shea and Sleeman (1973) have developed a conceptual framework useful for viewing adaptive teaching systems that are, in addition, self-improving. The biofeedback training system described in this paper corresponds to the intermediate level of their teaching system hierarchy. Programs at this level employ a fixed

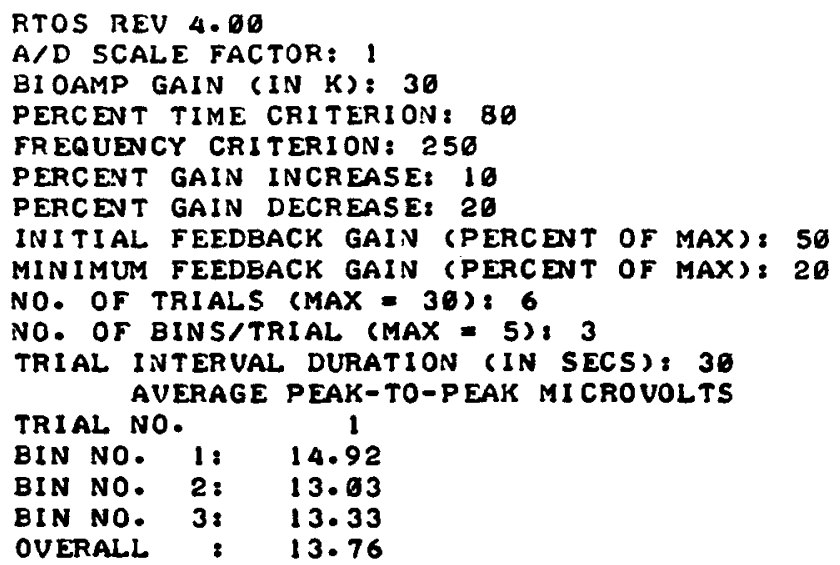

TRIAL NO.

BIN NO. 1: 14.65

BIN NO. 2: 13.13

BIN NO. 3: 14.88

OVERALL: 14.19

TRIAL NO.

BIN NO. I:

BIN NO. 2: 12.83

14.67

BIN NO. 3: 12.96

OVERALL : 13.49

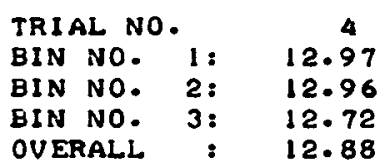

TRIAL NO. 5

BIN NO. 2: 27.67

BIN NO. $3: \quad 27.56$

OVERALL : 27.57

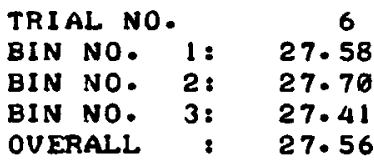

$\begin{array}{ll}\text { GAINS } \\ 1 & 49.80 \\ 2 & 29.80 \\ 3 & 40.80 \\ 4 & 49.80 \\ 5 & 29.80 \\ 6 & 20.00\end{array}$

Figure 4. Console record of shaping training session.

strategy by which task characteristics are adapted to the individual.

In the present system, a separate FORTRAN program implements each adaptive strategy. A training strategy implies a set of assertions relating strategy characteristics 
and their effects on training progress. Ultimately, a data base of these assertions could be updated on-line and the training system would be self-improving. O'Shea and Sleeman have identified techniques to implement this upper level of teaching system hierarchy. In effect, the system would evaluate the results of mini-experiments with various strategy versions within a session and modify the strategy accordingly. Development of adaptive biofeedback training systems along these lines provides a means to effectively exploit the unique capabilities of the on-line computer in this important treatment area.

\section{REFERENCES}

Blanchard, E. B., \& Young, L. D. Clinical applications of biofeedback training. Archives of General Psychiatry,
$1974,30,573-589$.

Budzynski, T. H., Stoyva, J. M., \& Adler, C. S. Feedbackinduced muscle relaxation: Application to tension headache. Joumal of Behavior Therapy and Experimental Psychiatry, 1970, 1, 205-211.

Coursey, R. D. Electromyograph feedback as a relaxation technique. Journal of Consulting and Clinical Psychology, $1975,43,825-834$.

Cox, D. J., Freundlich, A., \& Meyer, R. G. Differential effectiveness of electromyographic feedback, verbal relaxation instructions and medication placebo. Joumal of Consulting and Clinical Psychology, 1975, 43, 892-898.

O'SheA, T., \& Sleeman, D. H. A design for an adaptive self-improving teaching system. In J. Rose (Ed.), Advances in cybernetics and systems (Vol. 3). London: Gordon \& Breach, 1973.

WEIss, D. J. Strategies of adaptive ability measurement. Research Report 74-5, Psychometric Methods Program, Department of Psychology, University of Minnesota, 1974. (AD A004270) 